\title{
Single-Molecule Sandwich Immunoassay for Quantification of Alpha-Fetoprotein Based on Evanescent Field-Enhanced Fluorescence Imaging
}

\author{
Seungah Lee and Seong Ho Kang \\ Department of Applied Chemistry, College of Applied Science, Kyung Hee University, Gyeonggi-do, \\ Yongin-si 446-701, Republic of Korea \\ Correspondence should be addressed to Seong Ho Kang, shkang@khu.ac.kr
}

Received 2 October 2012; Accepted 7 November 2012

Academic Editor: Haiyan Li

Copyright ( $\odot 2012$ S. Lee and S. H. Kang. This is an open access article distributed under the Creative Commons Attribution License, which permits unrestricted use, distribution, and reproduction in any medium, provided the original work is properly cited.

\begin{abstract}
A highly sensitive immunosensor based on a gold nanopatterned chip was developed for accurate determination of alphafetoprotein (AFP) via total internal refection fluorescence microscopy (TIRFM). The surface of the gold nanopatterned chips was modified with dithiobis(succinimidyl propionate) and protein A/G for immobilization of the AFP antibody. The immunoassay created a sandwich of antigen between the AFP antibody on the chip that was modified with protein A/G, and the secondary antibody, a monoclonal anti-human-AFP labeled with biotin (biotin-labeled anti-AFP). AFP concentration was determined based on evanescent field fluorescence signal, which was generated by interaction between biotin-labeled anti-AFP and a streptavidinlabeled fluorescence dye. AFP concentration could be measured in a wide dynamic linear range of $720 \mathrm{zM}-10 \mathrm{nM}$ with a detection limit of $720 \mathrm{zM}$. A significant enhanced sensitivity ( 40,000-fold) was achieved with the AFP-nanoarray chip compared to conventional chemiluminescence immunosensors. The immunoassay exhibited a wide detection range and high sensitivity and accuracy, qualities valuable for clinical assay of AFP.
\end{abstract}

\section{Introduction}

Since the introduction of sandwich assays using monoclonal antibodies, various immunoassays have been introduced with automated analysis and increased specificity [1]. However, many immunoassay methods such as enzyme-linked immunosorbent assay (ELISA), radioimmunoassay (RIA), and single radial immunodiffusion have disadvantages such as being time-consuming procedures using expensive instrumentation with complicated separation and labeling steps, and potential dangers (e.g., radiation hazards) or expensive materials [2]. New techniques such as electrochemistry [3], chemiluminescence [4], piezoelectricity [5], surface plasmon resonance (SPR) [6], and sandwich immunoassays based on nanoarray protein chips $[7,8]$ have attracted interests because of their characteristics. Specifically, nanoarray protein chips offer a sensitive, accurate, quantitative, and simple alternative methodology for determination of tumor markers.

Alpha-fetoprotein (AFP) is a $70 \mathrm{kDa}$ oncofetal glycoprotein of 591 amino acids. It contains a single asparagine-linked (Asn233) carbohydrate chain that is a known biomarker for hepatocellular carcinoma (HCC) [9-12]. The association between serum AFP and HCC has been extensively described [13-16]. AFP has been a diagnostic test for HCC since the 1970s, when most patients with HCC were diagnosed at an advanced stage with clinical symptoms [17]. AFP is suggested to function as a transport molecule for several different ligands and various drugs $[18,19]$ and to have immunosuppressive activity and a role in regulation of cell proliferation [20]. The first conditionally quantitative serum assays for AFP were introduced in 1971 [21]. Several approaches have attempted to enhance the techniques of SPR detection [22] such as bioluminescent sandwich 


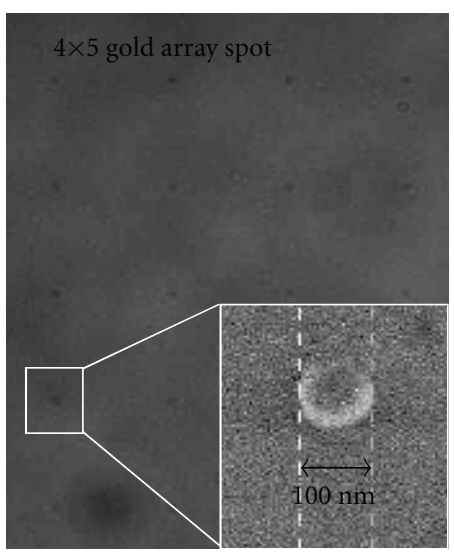

(a)

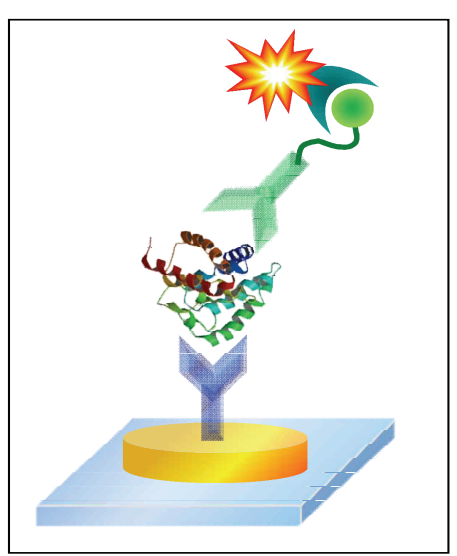

(b)

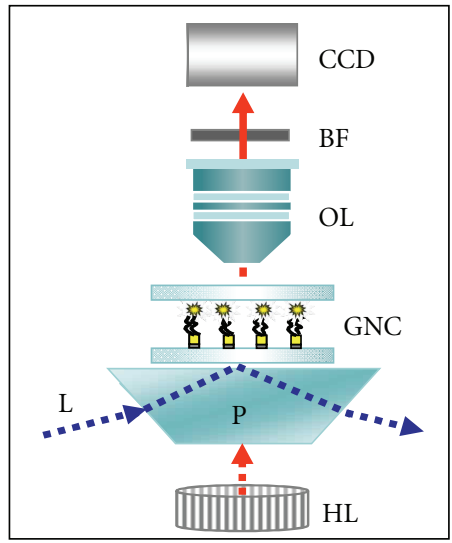

(c)

FIGURE 1: (a) DIC image of gold nanopatterned AFP chip with a spot diameter of $100 \mathrm{~nm}$ and (inner) SEM image of individual gold spots. (b) Schematic diagram of the AFP sandwich fluorescence immunoassay. (c) Schematic diagram showing the TIRFM detection system. L: laser; HL: halogen lamp; P: transmitted all-side polished dove-type prism; GNC: gold nanopatterned chip; OL: objective lens; BF: band-pass filter; C: charge-coupled device.

immunoassays [23], electrochemical immunoassays [24], and chemiluminescence resonance energy transfer [25]. However, the sensitivities for these assays are still poor [26].

In this study, a sandwich immunoassay using gold nanopatterned protein chips was developed for quantitative detection of tumor markers such as AFP in serum. A total internal reflection fluorescence microscopy (TIRFM) technique based on evanescent field fluorescence imaging was applied for trace analysis of AFP with a wide dynamic linear range to use in clinical diagnosis. The relationship between evanescent field-fluorescence signal and AFP concentration showed excellent and extensive linearity. The method was successfully applied to determine AFP in human serum.

\section{Experimental Details}

2.1. Reagent Preparation. Dimethyl sulfoxide (DMSO) and glycine were from Sigma-Aldrich Inc. (St. Louis, MO, USA). Dithiobis(succinimidyl propionate) (DSP) and protein A/G were from Pierce (Rockford, IL, USA). Tris (base) was from Mallinckrodt Baker, Inc. (Phillipsburg, NJ, USA). StabilGuard was from SurModics (Eden Prairie, MN, USA). Alexa Fluor 488 streptavidin was obtained from Molecular Probes (Eugene, OR, USA). Human AFP antigen, monoclonal antibody to human AFP (5H7), and monoclonal antibody to human AFP labeled with biotin (biotin-labeled anti-AFP, 4A3), were from Biodesign International (ME, USA). Normal human serum samples were isolated from blood by centrifugation at $2,000 \mathrm{rpm}$ for $15 \mathrm{~min}$ at $2{ }^{\circ} \mathrm{C}$. To mimic clinical conditions, a standard AFP sample of $20 \mathrm{fM}$ was spiked into $1: 10^{4}$ diluted normal human serum at a three-to-one ratio. Before use, $1 \times$ PBS buffer solution $(\mathrm{pH}$ 7.4; $137 \mathrm{mM} \mathrm{NaCl}, 2.7 \mathrm{mM} \mathrm{KCl}, 4.3 \mathrm{mM} \mathrm{Na}_{2} \mathrm{HPO}_{4}, 1.4 \mathrm{mM}$ $\mathrm{KH}_{2} \mathrm{PO}_{4}$ ) was filtered through a $0.2-\mu \mathrm{m}$ membrane filter and photobleached overnight using a UV-B lamp (G15TE, 280$315 \mathrm{~nm}$, Philips, The Netherlands).
2.2. Gold Nanopatterned Chips. A gold nanopatterned substrate was designed as shown in Figure 1(a) and fabricated by the National Nanofab Center (Daejeon, Republic of Korea). Four-inch soda-lime glass wafers from Winwin Tech (Bucheon, Republic of Korea) were used to make $4 \times 5$ nanoarrays with $100 \mathrm{~nm}$ diameter spots (SEM in Figure 1(a)) with a $10 \mu \mathrm{m}$ pitch. Gold spots were deposited on the glass substrate by an electron beam evaporator. Substrates were coated with a $5 \mathrm{~nm}$ adhesive layer of chromium (99.997\% purity) at a rate of $0.1 \mathrm{~nm} / \mathrm{s}$, followed by deposition of a $20 \mathrm{~nm}$ layer of gold $(99.997 \%$ purity) at a rate of $0.1 \mathrm{~nm} / \mathrm{s}$. Before linker deposition, chips were immersed in acetone (99.5\% purity) for $30 \mathrm{~s}$, followed by isopropyl alcohol (99.9\% purity) for $30 \mathrm{~s}$. Gold nanopatterned chips were exposed to piranha solution $\left(1: 1=\mathrm{H}_{2} \mathrm{SO}_{4}: 30 \% \mathrm{H}_{2} \mathrm{O}_{2}\right)$ for $30 \mathrm{~min}$, rinsed with deionized water, and dried under a stream of nitrogen. Before use, chips were stored in a desiccator.

\subsection{AFP Single-Molecule Sandwich Immunoassay on Gold} Nanopatterned Chips. The analytical procedure for sandwich immunoassay of AFP on a gold substrate is schematically depicted in Figure 1(b). Gold patterned chips were immersed in $4 \mathrm{mg} / \mathrm{mL}$ DSP in DMSO for $30 \mathrm{~min}$, then rinsed with DMSO and deionized water. Addition of $0.1 \mathrm{mg} / \mathrm{mL}$ of protein $A / G$, which binds to the heavy chains of the antibody Fc region, was used to uniformly orient the antibodies for $1 \mathrm{~h}$. Unreacted succinimide groups were blocked with $10 \mathrm{mM}$ Tris ( $\mathrm{pH} 7.5)$ and $1 \mathrm{M}$ glycine for $30 \mathrm{~min}$. Chips were incubated with StabilGuard for $30 \mathrm{~min}$ to stabilize bound proteins, then rinsed briefly with a few drops of deionized water. Chips were incubated with $20 \mu \mathrm{L}$ of $2 \mu \mathrm{g} / \mathrm{mL}$ monoclonal antibody to human AFP (5H7) in PBS (pH 7.4) for $1 \mathrm{~h}$. After washing, AFP standard protein that was diluted to various concentrations, or normal or spiked clinical samples were incubated on chips for $1 \mathrm{~h}$. The incubation time of the sample with $720 \mathrm{zM}$ AFP was increased to $5 \mathrm{~h}$ to allow sufficient time for Brownian motion. Reaction with 
TABLE 1: Comparison of detection limits between AFP-nanoarray chips and other methods.

\begin{tabular}{|c|c|c|c|}
\hline Method & Dynamic range $(\mathrm{ng} / \mathrm{mL})$ & LOD (ng/mL) & References \\
\hline SPR & $1.0-200(14 \mathrm{pM}-2.8 \mathrm{nM})$ & $0.65(9.1 \mathrm{pM})$ & {$[22]$} \\
\hline BL immunoassay I & $0.01-100(140 \mathrm{fM}-1.4 \mathrm{nM})$ & $0.01(140 \mathrm{fM})$ & {$[23]$} \\
\hline BL immunoassay II & $0.02-200(280 \mathrm{fM}-2.8 \mathrm{nM})$ & $0.02(280 \mathrm{fM})$ & {$[28,29]$} \\
\hline CRET & 5-70 (70 pM-980 pM) & $2.50(35 \mathrm{pM})$ & {$[25]$} \\
\hline FRET inhibition assay & $0.8-45(11.2 \mathrm{pM}-0.63 \mathrm{nM})$ & $0.41(5.74 \mathrm{pM})$ & {$[30]$} \\
\hline Pz immunoassay & 20-640 (280 pM-8.96 nM) & $20(280 \mathrm{pM})$ & {$[31]$} \\
\hline EC immunoassay I & $0.5-80(7 \mathrm{pM}-1.12 \mathrm{nM})$ & $0.25(3.5 \mathrm{pM})$ & {$[32]$} \\
\hline EC immunoassay II & $0.1-30(1.4 \mathrm{pM}-420 \mathrm{pM})$ & $0.018(252 \mathrm{fM})$ & {$[33]$} \\
\hline EC immunoassay III & $0.01-200(140 \mathrm{fM}-2.8 \mathrm{nM})$ & $0.004(56 \mathrm{fM})$ & {$[34]$} \\
\hline EC immunoassay IV & $1.0-10(14 \mathrm{pM}-140 \mathrm{pM})$ & $0.70(9.8 \mathrm{pM})$ & {$[35]$} \\
\hline ECL immunoassay & $0.002-32(28 \mathrm{fM}-448 \mathrm{pM})$ & $0.002(28 \mathrm{fM})$ & {$[36]$} \\
\hline CL immunoassay & $0.01-0.5(140 \mathrm{fM}-7 \mathrm{pM})$ & $0.005(70 \mathrm{fM})$ & {$[37]$} \\
\hline AFP-nanoarray chip & $50 \times 10^{-9}-714.3(720 \mathrm{zM}-10 \mathrm{nM})$ & $50 \times 10^{-9}(720 \mathrm{zM})$ & This work \\
\hline
\end{tabular}

Indication: SPR: surface plasmon resonance; BL: bioluminescent; CRET: chemiluminescence resonance energy transfer; FRET: fluorescence resonance energy transfer; Pz: piezoelectric; EC: electrochemical; ECL: electrogenerated chemiluminescence; CL: chemiluminescence; LOD: limit of detection.

$20 \mu \mathrm{L}$ of $2 \mu \mathrm{g} / \mathrm{mL}$ biotin-labeled anti-AFP (4A3) was for $1 \mathrm{~h}$. To detect biotin-labeled anti-AFP, $20 \mu \mathrm{L}$ of Alexa Fluor 488 streptavidin $(2 \mu \mathrm{g} / \mathrm{mL})$ was added to chips and incubated for $30 \mathrm{~min}$. Chips were washed in $100 \mathrm{~mL} 1 \times$ PBS for $2 \mathrm{~min}$ and rinsed briefly with deionized water at each step. All reactions were carried out at room temperature with agitation.

2.4. Total Internal Reflection Microscopic System. A schematic diagram of the TIRFM system is in Figure 1(c). An upright Olympus BX51 microscope (Olympus Optical Co., Ltd., Tokyo, Japan) with an Olympus 100× UPLFL objective lens (oil type, 1.3 N.A., W.D. $0.1 \mathrm{~mm}$ ) was used. A $520 / 10 \mathrm{~nm}$ band-pass filter from Semrock (Rochester, NY, USA) was coordinated with the use of $473 \mathrm{~nm}$ laser excitation during imaging. Fluorescence images were captured by an electronmultiplying, cooled charge-coupled device (EM-CCD) camera (QuantEM 512SC, Photometrics, AZ, USA) equipped with a Uniblitz mechanical shutter (Vincent Associates, Rochester, NY, USA) with an exposure time of $100 \mathrm{~ms}$. All quantitative analysis of data and image acquisition used MetaMorph 7.1 software (Universal Imaging Co., Downing Town, PA, USA).

\section{Results and Discussion}

A single-molecule sandwich immunoassay for sensitive detection of AFP by evanescent field-enhanced fluorescence was designed. The sensitivity of the AFP assay could calculate the detection limit of $720 \mathrm{zM}$ using $100 \mathrm{~nm}$ gold nanopatterned chips. Size reduction and site-specific labeling of antibodies to create a surface with high functional capacity increases the sensitivity of an immunoassay [27]. Furthermore, the $100 \mathrm{~nm}$ gold array chips showed no quenching of fluorescence dyes and had increased sensitivity. Under optimal conditions, the sandwich immunoassay had high sensitivity and a wide dynamic range for monitoring on a single-molecule level.

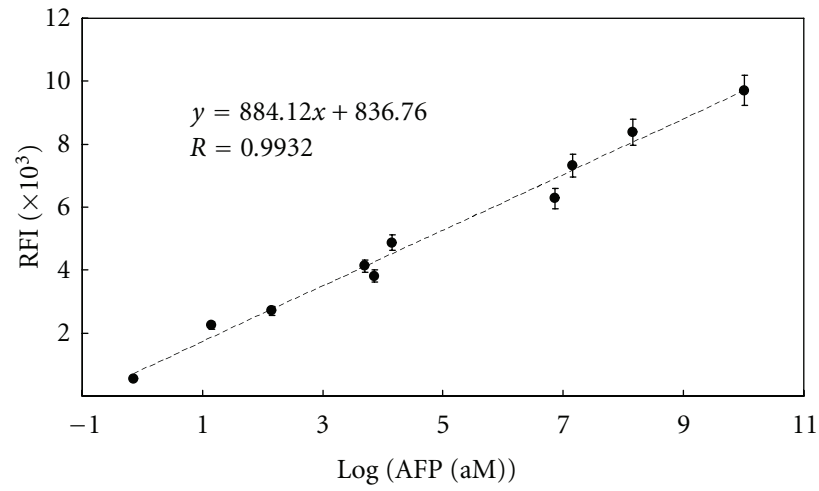

FIGURE 2: Calibration curve with linear range of standard AFP concentrations produced by serial dilutions from $720 \mathrm{zM}$ to $10 \mathrm{nM}$. Relative fluorescence intensity (RFI) was corrected by background subtraction.

The increase in relative fluorescence intensity (RFI) was proportional to AFP concentration (Figure 2), and the linear response range was $720 \mathrm{zM}$ to $10 \mathrm{nM}$ (linear regression equation, $y=884.12 x+836.76, R=0.9932)$ with a low detection limit of $720 \mathrm{zM}$ and a signal-to-noise ratio $(S / N)$ of 3 (Table 1$)$. The AFP-nanoarray chip method showed 40,000 times higher sensitivity than other methods (i.e., surface plasmon resonance, bioluminescent immunoassay, electrochemical immunoassay, and chemiluminescence immunoassay). These results showed that the proposed method was highly sensitive, especially for ultralow levels of AFP.

In addition, the wide quantification range $(720 \mathrm{zM}$ to $10 \mathrm{nM}$ ) would be useful for healthy human serum, which has unestablished normal ranges for AFP. The normal range of AFP for adults and children is variously reported as under $50 \mathrm{ng} / \mathrm{mL}$ [38], under $10 \mathrm{ng} / \mathrm{mL}$ [39], and under $5 \mathrm{ng} / \mathrm{mL}$ [40]. Bader et al., Wang and $\mathrm{Xu}$ reported that the average concentration of AFP is about $25 \mathrm{ng} / \mathrm{mL}$ in healthy human 


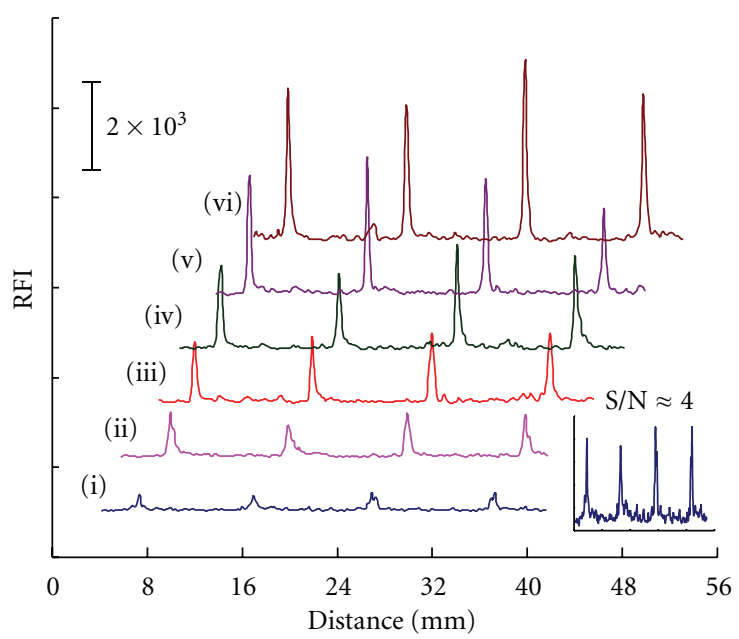

(a)

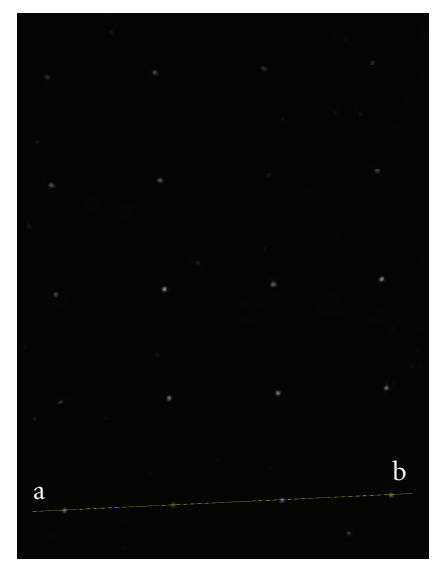

(b)

FIGURE 3: (a) Peak of fluorescence intensity of serially diluted AFP standard antigen reacted with a chip as "a" to "b" horizontal line in (b). (i) $14.3 \mathrm{aM}$; (ii) $7.2 \mathrm{fM}$; (iii) $14.3 \mathrm{fM}$; (iv) $7.2 \mathrm{pM}$; (v) $14.3 \mathrm{pM}$; (vi) $143 \mathrm{pM}$. RFI: relative fluorescence intensity.
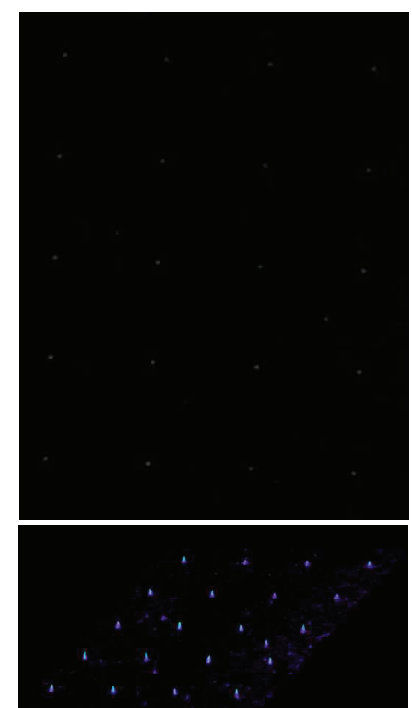

RFI
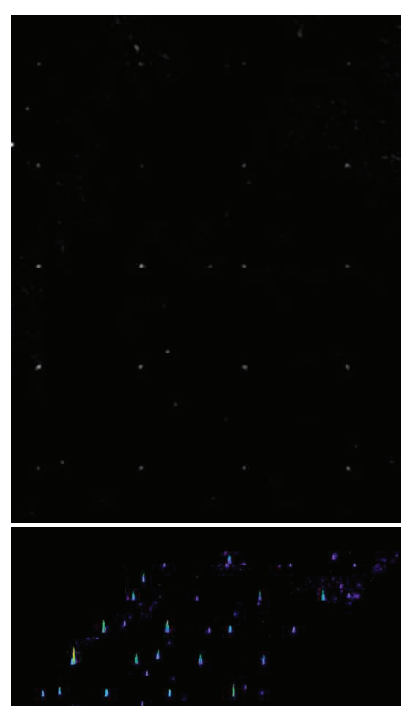

RFI

(a)

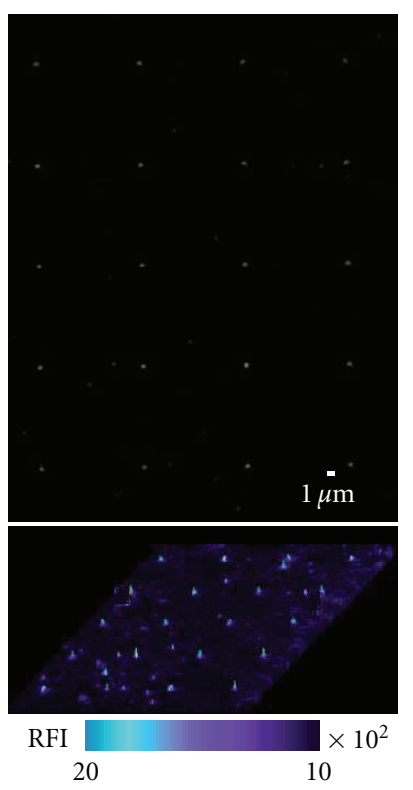

(c)

FIGURE 4: Evanescent field-enhanced fluorescence images via prism-type TIRFM of (a) standard AFP (AFP-positive sample), (b) normal (nonpathologic) human serum, and (c) AFP-spiked human serum on gold nanopatterned chip.

serum $[41,42]$. Ju et al. also reported a low average value of $3.4 \mathrm{ng} / \mathrm{mL}$ [43]. However, a level above $500 \mathrm{ng} / \mathrm{mL}$ of AFP in adults can be indicative of HCC, germ cell tumors, and metastatic liver cancer.

The assay method for quantitative analysis was based on evanescent field-enhanced fluorescence imaging via prismtype TIRFM. First, we selected signal regions and background regions with the same area. The sum of TIRF intensities of occupied pixels per single spot was corrected by background subtraction and RFI was calculated. Figure 3(a) shows the peak of fluorescence intensity of serial diluted AFP standard antigen reacted on chip. The peak width was greater than the spot diameter of $100 \mathrm{~nm}$ because of fluorescence imaging. The peak shows a moderate increase with increasing AFP concentration from $14.3 \mathrm{aM}$ to $143 \mathrm{pM}$.

In this study, samples including standard AFP antigen, normal human serum, and human serum with added standard AFP antigen were evaluated using TIRFM and single-molecule sandwich immunoassay chips. The AFP standard (AFP, positive sample) (Figure 4(a), $1.42 \mathrm{pg} / \mathrm{mL}=$ $20 \mathrm{fM}$ ), normal (nonpathologic) human serum (Figure 4(b), $0.13 \mathrm{pg} / \mathrm{mL}=1.8 \mathrm{fM})$, and the sample of human serum 
spiked with AFP (Figure 4(c), $1.16 \mathrm{pg} / \mathrm{mL}=16.3 \mathrm{fM}$; theoretical, $1.1 \mathrm{pg} / \mathrm{mL}=15.4 \mathrm{fM}$ ) were analyzed using gold nanopatterned chips. The results indicated that the sandwich immunoassay using the gold nanopatterned chips gave the high accuracy and sensitivity required for the quantification of biomarkers in human serum samples.

Specificity is an important factor in practical use of immunoassays. AFP is closely related to albumin, both genetically and structurally. The amino acid sequences of AFP and albumin have extensive homology, and the genes coding for the proteins are localized to the same area of human chromosome 4 (4q11-q13) [44]. Since the 1980s, research on monoclonal antibodies with unique specificity for individual binding sites on antigens has been used to improve the sensitivity and specificity of AFP determination [45]. Ding et al. evaluated the selectivity of an immunosensor with four kinds of potential interferents, including Lglutamic acid, bovine serum albumin, hemoglobin, and Dglucose [32]. Chan et al. showed specificity satisfactory with paired monoclonal antibodies for AFP [46]. The monoclonal antibodies against human AFP from Biodesign International (5H7 and 4A3) that we used for the AFP sandwich assay specifically recognized the human AFP molecule [47]. This allowed us to ignore the negligible effects of interfering antigens in the AFP sandwich immunoassay.

\section{Conclusions}

We developed a single-molecule sandwich immunoassay on gold nanopatterned chips that was highly sensitive for AFP detection in human serum. The method has a wide range of quantitation and could be applied for testing healthy human serum with the normal range of AFP that has been reported as $47.6 \mathrm{pM}-700 \mathrm{pM}$. The method could be used to diagnose AFP-negative or AFP-positive human serum from pathological clinical samples.

The linear response range of the assay for AFP concentration was $720 \mathrm{zM}$ to $10 \mathrm{nM}$ with a correlation coefficient of 0.9932 . The detection limit of $50 \times 10^{-9} \mathrm{ng} / \mathrm{mL}(720 \mathrm{zM})$ with a $S / N$ of 3 was in linear range of the calibration curve, and much lower than LODs from $0.004 \mathrm{ng} / \mathrm{mL}$ to $20 \mathrm{ng} / \mathrm{mL}$ reported for other methods [28-31, 33-35]. For the AutoDELFIA hAFP immunoassay for the quantitative determination of hAFP, Mannings et al. established that falsely low AFP concentrations occur in $2.8 \%$ of samples with AFP concentrations $<15 \mathrm{kU} / \mathrm{L}(13.8 \mathrm{ng} / \mathrm{mL}=193 \mathrm{pM})$ due to immunoassay interference [48]. Our results showed that a sandwich immunoassay chip for quantitative analysis of AFP by evanescent field-enhanced fluorescence imaging was simple and sufficiently sensitive for determination of AFP in human serum samples. The assay had good precision and accuracy at the single-molecule level. The new immunoassay is expected to be widely useful for highly sensitive clinical analysis and other biotechnology applications.

\section{Conflict of Interests}

The authors have declared no conflict of interests.

\section{Acknowledgment}

This research was supported by a postdoctoral fellowship Grant from Kyung Hee University in 2011 (KHU-20110212).

\section{References}

[1] D. W. Chan and S. Sell, "Tumor markers," in Tietz Text Book of Clinical Chemistry, C. A. Burtis and E. R. Ashwood, Eds., pp. 897-927, WB Saunders Company, Philadelphia, Pa, USA, 2nd edition, 1994.

[2] C. M. Sturgeon, "Tumor markers in the laboratory: closing the guideline-practice gap," Clinical Biochemistry, vol. 34, no. 5, pp. 353-359, 2001.

[3] M. S. Wilson, "Electrochemical immunosensors for the simultaneous detection of two tumor markers," Analytical Chemistry, vol. 77, no. 5, pp. 1496-1502, 2005.

[4] T. Konry, A. Novoa, Y. Shemer-Avni et al., "Optical fiber immunosensor based on a poly(pyrrole-benzophenone) film for the detection of antibodies to viral antigen," Analytical Chemistry, vol. 77, no. 6, pp. 1771-1779, 2005.

[5] B. Zuo, S. Li, Z. Guo, J. Zhang, and C. Chen, "Piezoelectric immunosensor for SARS-associated coronavirus in sputum," Analytical Chemistry, vol. 76, no. 13, pp. 3536-3540, 2004.

[6] R. Kurita, Y. Yokota, Y. Sato, F. Mizutani, and O. Niwa, "On-chip enzyme immunoassay of a cardiac marker using a microfluidic device combined with a portable surface plasmon resonance system," Analytical Chemistry, vol. 78, no. 15, pp. 5525-5531, 2006.

[7] S. Lee, N. P. Cho, J. D. Kim, H. Jung, and S. H. Kang, "An ultrasensitive nanoarray chip based on single-molecule sandwich immunoassay and TIRFM for protein detection in biologic fluids," Analyst, vol. 134, no. 5, pp. 933-938, 2009.

[8] S. Lee, S. Lee, Y. H. Ko et al., "Quantitative analysis of human serum leptin using a nanoarray protein chip based on singlemolecule sandwich immunoassay," Talanta, vol. 78, no. 2, pp. 608-612, 2009.

[9] H. Yoshima, T. Mizuochi, M. Ishii, and A. Kobata, "Structure of the asparagine-linked sugar chains of $\alpha$-fetoprotein purified from human ascites fluid," Cancer Research, vol. 40, no. 11, pp. 4276-4281, 1980.

[10] G. J. Mizejewski, “ $\alpha$-fetoprotein as a biologic response modifier: relevance to domain and subdomain structure," Proceedings of the Society for Experimental Biology and Medicine, vol. 215, no. 4, pp. 333-362, 1997.

[11] E. Alpert, R. Hershberg, P. H. Schur, and K. J. Isselbacher, "Alpha-fetoprotein in human hepatoma: improved detection in serum, and quantitative studies using a new sensitive technique," Gastroenterology, vol. 61, no. 2, pp. 137-143, 1971.

[12] X. W. Wang and H. Xie, "Alpha-fetoprotein enhances the proliferation of human hepatoma cells in vitro," Life Sciences, vol. 64, no. 1, pp. 17-23, 1998.

[13] G. I. Abelev, S. D. Perova, N. I. Khramkova, Z. A. Postnikova, and I. S. Irlin, "Production of embryonal alpha-globulin by transplantable mouse hepatomas," Transplantation, vol. 1, pp. 174-180, 1963.

[14] M. E. Alpert, J. Uriel, and B. de Nechaud, "Alpha-1 fetoglobulin in the diagnosis of human hepatoma," The New England Journal of Medicine, vol. 278, no. 18, pp. 984-986, 1968.

[15] L. R. Purves, M. MacNab, E. W. Geddes, and I. Bersohn, "Serum-alpha-foetoprotein and primary hepatic cancer," The Lancet, vol. 1, no. 7548, pp. 921-922, 1968. 
[16] J. B. Smith and D. Todd, "Foetoglobin and primary liver cancer," The Lancet, vol. 2, no. 7572, p. 833, 1968.

[17] M. C. Kew, "Alpha-fetoprotein," in Modern Trends in Gastroenterology, A. E. Read, Ed., vol. 5, p. 91, Butterworths, London, UK, 1975.

[18] H. F. Deutsch, "Chemistry and biology of $\alpha$-fetoprotein," Advances in Cancer Research, vol. 56, pp. 253-312, 1991.

[19] G. J. Mizejewski, "Alpha-fetoprotein structure and function: relevance to isoforms, epitopes, and conformational variants," Experimental Biology and Medicine, vol. 226, no. 5, pp. 377408, 2001.

[20] A. A. Terentiev and N. T. Moldogazieva, "Structural and functional mapping of $\alpha$-fetoprotein," Biochemistry, vol. 71, no. 2, pp. 120-132, 2006.

[21] E. Ruoslahti and M. Seppälä, "Studies of carcino-fetal proteins. 3. Development of a radioimmunoassay for -fetoprotein. Demonstration of -fetoprotein in serum of healthy human adults," International Journal of Cancer, vol. 8, no. 3, pp. 374383, 1971.

[22] R. P. Liang, G. H. Yao, L. X. Fan, and J. D. Qiu, "Magnetic $\mathrm{Fe}_{3} \mathrm{O}_{4} @ \mathrm{Au}$ composite-enhanced surface plasmon resonance for ultrasensitive detection of magnetic nanoparticle-enriched $\alpha$-fetoprotein," Analytica Chimica Acta, vol. 737, no. 6, pp. 22 28, 2012.

[23] S. Inouye and J. Sato, "Purification of histidine-tagged aequorin with a reactive cysteine residue for chemical conjugations and its application for bioluminescent sandwich immunoassays," Protein Expression and Purification, vol. 83, no. 2, pp. 205-210, 2012.

[24] B. Zhang, D. Tang, B. Liu, H. Chen, Y. Cui, and G. Chen, "GoldMag nanocomposite-functionalized graphene sensing platform for one-step electrochemical immunoassay of alphafetoprotein," Biosensors and Bioelectronics, vol. 28, no. 1, pp. 174-180, 2011.

[25] X. Huang and J. Ren, "Gold nanoparticles based chemiluminescent resonance energy transfer for immunoassay of alpha fetoprotein cancer marker," Analytica Chimica Acta, vol. 686, no. 1-2, pp. 115-120, 2011.

[26] J. Bruix, M. Sherman, J. M. Llovet et al., "Clinical management of hepatocellular carcinoma. Conclusions of the barcelona2000 EASL conference," Journal of Hepatology, vol. 35, no. 3, pp. 421-430, 2001.

[27] J. Ylikotila, L. Välimaa, M. Vehniäinen, H. Takalo, T. Lövgren, and K. Pettersson, "A sensitive TSH assay in spot-coated microwells utilizing recombinant antibody fragments," Journal of Immunological Methods, vol. 306, no. 1-2, pp. 104-114, 2005.

[28] S. Inouye and J. I. Sato, "Comparison of luminescent immunoassays using biotinylated proteins of aequorin, alkaline phosphatase and horseradish peroxidase as reporters," Bioscience, Biotechnology and Biochemistry, vol. 72, no. 12, pp. 3310-3313, 2008.

[29] S. Inouye and J. I. Sato, "Recombinant aequorin with a reactive cysteine residue for conjugation with maleimide-activated antibody," Analytical Biochemistry, vol. 378, no. 1, pp. 105$107,2008$.

[30] B. Y. Wu, H. F. Wang, J. T. Chen, and X. P. Yan, "Fluorescence resonance energy transfer inhibition assay for $\alpha$-fetoprotein excreted during cancer cell growth using functionalized persistent luminescence nanoparticles," Journal of the American Chemical Society, vol. 133, no. 4, pp. 686-688, 2011.

[31] B. Zhang, X. Zhang, H. H. Yan, S. J. Xu, D. H. Tang, and W. L. Fu, "A novel multi-array immunoassay device for tumor markers based on insert-plug model of piezoelectric immunosensor," Biosensors and Bioelectronics, vol. 23, no. 1, pp. 19-25, 2007.

[32] C. Ding, F. Zhao, R. Ren, and J. M. Lin, "An electrochemical biosensor for $\alpha$-fetoprotein based on carbon paste electrode constructed of room temperature ionic liquid and gold nanoparticles," Talanta, vol. 78, no. 3, pp. 1148-1154, 2009.

[33] R. P. Liang, Z. X. Wang, L. Zhang, and J. D. Qiu, "A label-free amperometric immunosensor for alpha-fetoprotein determination based on highly ordered porous multi-walled carbon nanotubes/silica nanoparticles array platform," Sensors and Actuators B, vol. 166-167, pp. 569-575, 2012.

[34] N. Gan, L. Jia, and L. Zheng, "A novel sandwich electrochemical immunosensor based on the DNA-derived magnetic nanochain probes for alpha-fetoprotein," Journal of Automated Methods and Management in Chemistry, vol. 2011, Article ID 957805, 7 pages, 2011.

[35] B. Su, J. Tang, J. Huang et al., "Graphene and nanogoldfunctionalized immunosensing interface with enhanced sensitivity for one-step electrochemical immunoassay of alphafetoprotein in human serum," Electroanalysis, vol. 22, no. 22, pp. 2720-2728, 2010.

[36] Q. Liu, M. Han, J. Bao, X. Jiang, and Z. Dai, “CdSe quantum dots as labels for sensitive immunoassay of cancer biomarker proteins by electrogenerated chemiluminescence," Analyst, vol. 136, no. 24, pp. 5197-5203, 2011.

[37] J. Lin, Y. Zhao, Z. Wei, and W. Wang, "Chemiluminescence immunoassay based on dual signal amplification strategy of $\mathrm{Au} /$ mesoporous silica and multienzyme functionalized mesoporous silica," Materials Science and Engineering B, vol. 176, no. 18, pp. 1474-1478, 2011.

[38] Y. S. Kim, S. H. Kim, J. K. Seong, B. S. Lee, H. Y. Jeong, and K. S. Song, "Gastric yolk sac tumor: a case report and review of the literature," Korean Journal of Internal Medicine, vol. 24, no. 2, pp. 143-146, 2009.

[39] D. Ball, E. Rose, and E. Alpert, "Alpha-fetoprotein levels in normal adults," American Journal of the Medical Sciences, vol. 303, no. 3, pp. 157-159, 1992.

[40] P. Sizaret, N. Martel, A. Tuyns, and S. Reynaud, "Mean $\alpha$ fetoprotein values of 1,333 males over 15 years by age groups," Digestion, vol. 15, no. 2, pp. 97-103, 1977.

[41] D. Bader, A. Riskin, O. Vafsi et al., "Alpha-fetoprotein in the early neonatal period-a large study and review of the literature," Clinica Chimica Acta, vol. 349, no. 1-2, pp. 15-23, 2004.

[42] X. W. Wang and B. Xu, "Stimulation of tumor-cell growth by alpha-fetoprotein," International Journal of Cancer, vol. 75, no. 4, pp. 596-599, 1998.

[43] H. Ju, G. Yan, F. Chen, and H. Chen, "Enzyme-linked immunoassay of $\alpha$-1-fetoprotein in serum by differential pulse voltammetry," Electroanalysis, vol. 11, no. 2, pp. 124-128, 1999.

[44] P. P. Minghetti, M. E. Harper, E. Alpert, and A. Dugaiczyk, "Chromosomal structure and localization of the human $\alpha$ fetoprotein gene," Annals of the New York Academy of Sciences, vol. 417, pp. 1-12, 1983.

[45] D. H. Bellet, J. R. Wands, K. J. Isselbacher, and C. Bohuon, "Serum $\alpha$-fetoprotein levels in human disease: perspective from a highly specific monoclonal radioimmunoassay," Proceedings of the National Academy of Sciences of the United States of America, vol. 81, no. 12, pp. 3869-3873, 1984.

[46] D. W. Chan, M. Kelsten, R. Rock, and D. Bruzek, "Evaluation of a monoclonal immunoenzymometric assay for alphafetoprotein," Clinical Chemistry, vol. 32, no. 7, pp. 1318-1322, 1986. 
[47] https://meridianlifescience.com/.

[48] L. Mannings, S. Trow, J. Newman, B. Nix, and C. Evans, "Interference in the autoDELFIA hAFP immunoassay and effect on second-trimester Down's syndrome screening," Annals of Clinical Biochemistry, vol. 48, no. 5, pp. 438-440, 2011. 

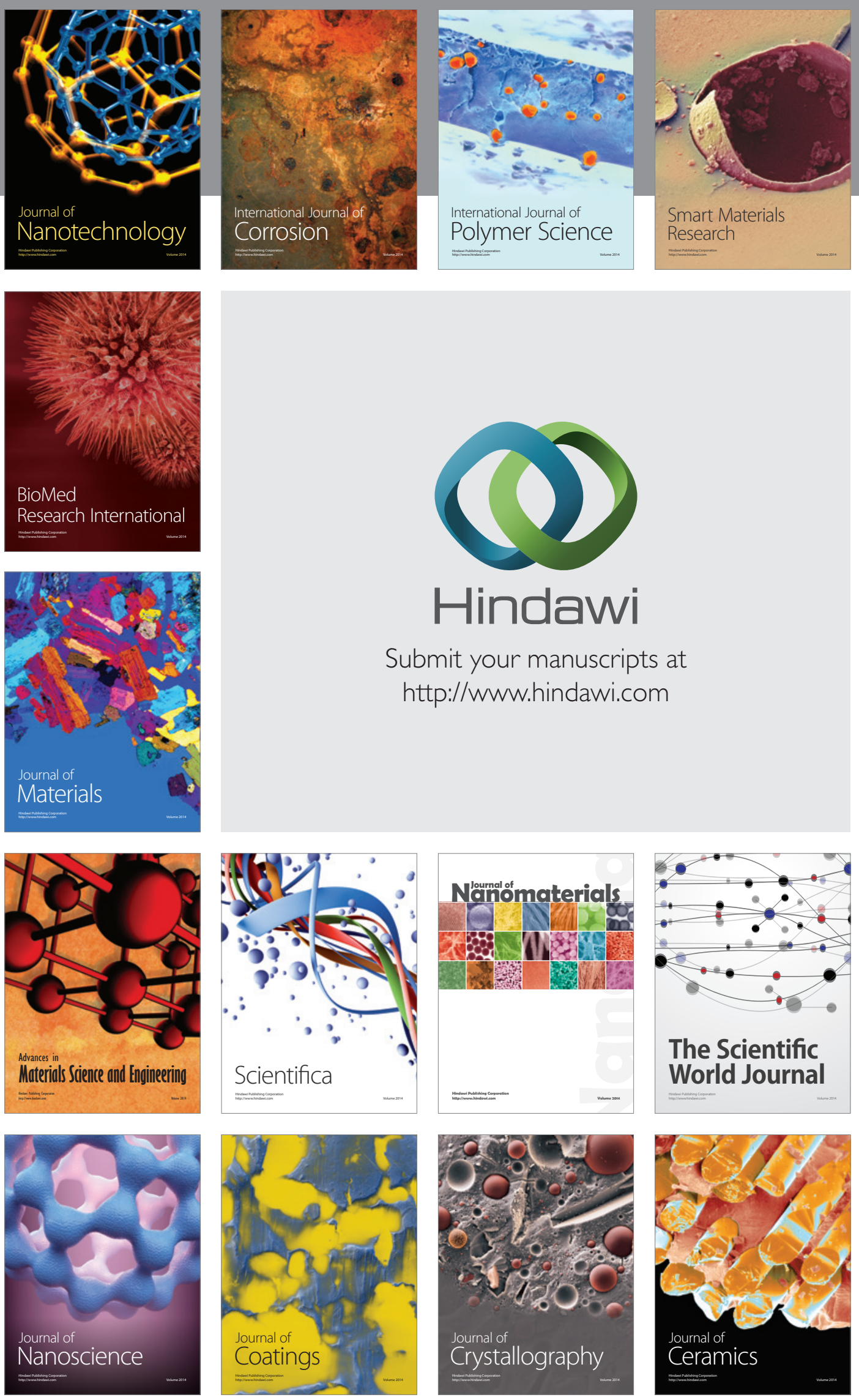

The Scientific World Journal

Submit your manuscripts at

http://www.hindawi.com

\section{World Journal}

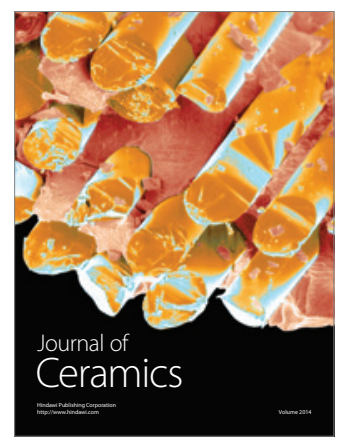

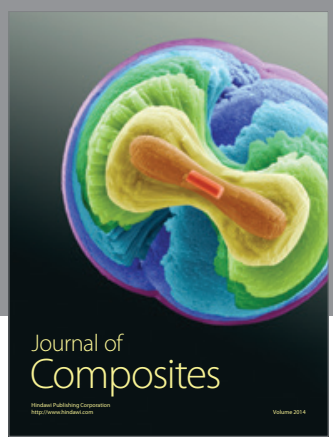
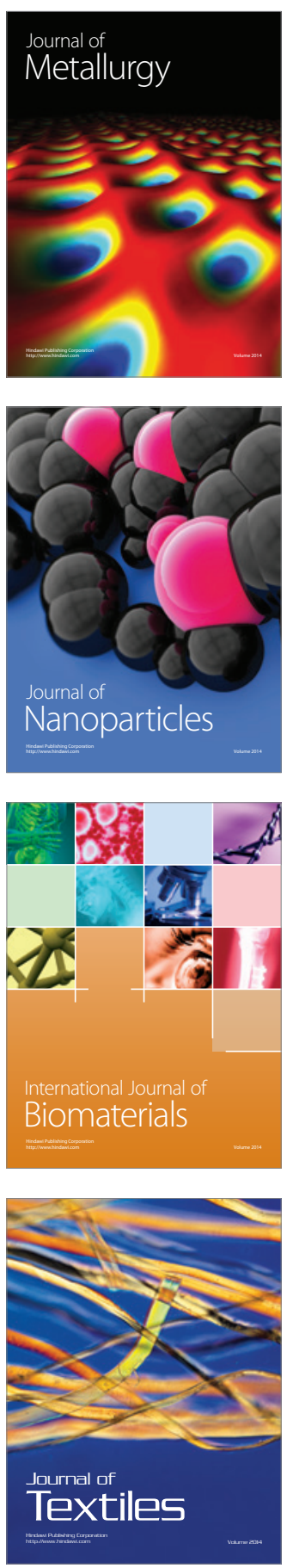